DOI: $10.17957 / \mathrm{IJAB} / 15.1741$

http://www.fspublishers.org

\title{
Mechanism of Action of Potato Glycoalkaloids against Fusarium solani
}

\author{
Jing He ${ }^{1,2^{*}}$, Tian-Tian Duo ${ }^{1}$, Wei Chen ${ }^{1}$ and Xiao-Yan Zhang ${ }^{1}$ \\ ${ }^{1}$ College of Forestry, Gansu Agricultural University, Lanzhou 730070, China \\ ${ }^{2}$ Agronomy College, Gansu Agricultural University, Lanzhou 730070, China \\ *For correspondence: hejing268@aliyun.com \\ Received 09 September 2020; Accepted 12 January 2021; Published 25 March 2021
}

\begin{abstract}
The antifungal mechanism of potato glycoalkaloids was studied using a sensitive species, Fusarium solani. The effects of potato glycoalkaloids extract on the ultrastructure, membrane permeability, contents of reducing sugar, soluble sugar, soluble protein and mycelial fat of Fusarium solani were determined. Potato glycoalkaloids significantly affected $F$. solani mycelial morphology, resulting in bubbly mycelial cell walls, incomplete outer layer, discontinuous cell membrane, disorganized structures of mitochondria and other organelles, and visible leakage of cell contents. Investigation of material metabolism indicated that potato glycoalkaloids disrupted selective permeability of mycelial cell membranes; In the treatment group, the soluble protein content increased from $66.50 \mathrm{~g} \mathrm{~mL}^{-1}$ to $169.51 \mathrm{~g} \mathrm{~mL}^{-1}$ for $0-6 \mathrm{~h}$, the soluble sugar content in extracellular fluid increased from $117.4 \mathrm{~g} \mathrm{~mL}^{-1}$ to $132.5 \mathrm{~g} \mathrm{~mL}^{-1}$ for $0-24 \mathrm{~h}$, which were much higher than that of the control group, hindered hydrolysis of reducing sugar, affected nutrient absorption and utilization and inhibited decomposition metabolism of mycelia. Thus, potato glycoalkaloids altered the morphology of fungal mycelia, destroyed cell membrane structure, increased mycelial cell membrane permeability, and caused cell contents leakage, resulting in effective inhibition of growth and metabolism of plant pathogenic fungus and so could decrease the occurrence of plant disease. (C) 2021 Friends Science Publishers
\end{abstract}

Keywords: Antifungal mechanism; Fusarium solani; Mycelial morphology; Plant disease; Potato glycoalkaloids

\section{Introduction}

Fusarium is one of the most important fungi in nature, and can survive in soil and plants during winter and summer, with wide distribution, diverse hosts, strong resistance, and rapid growth and reproduction (Du 2017). Fusarium solani is one of the most common Fusarium spp., which infects the host vascular tissue, destroys its conducting tissue, and produces toxins that harm crops during growth, development, and metabolism. To date, F. solani is one of the plant pathogens which are difficult to control in production, and can cause root diseases in various economic crops worldwide, such as white mulberry (Zhang 2013), Chinese angelica (Zhao et al. 2012), walnut (Zheng et al. 2016), medlar (Chen et al. 2017), wild pepper (Li et al. 2016), and pear (Tang et al. 2017). Fusarium solani can also cause fruit rot (Rampersad 2010) and deformity (Zhao et al. 2018), resulting in wilting and death of crops, affecting yield and quality, and producing huge economic losses. Currently, $F$. solani control depends on chemical fungicides such as carbendazim, mancozeb, thiram, cymoxanil-mancozeb, xinjunan acetate, or pyrazole-kresoxim-methyl (Wang et al. 2014; Chen et al. 2017; Tang et al. 2017). However, longterm usage of chemical fungicides can result in pesticide residues, environmental pollution, and disease resistance, leading to a series of adverse effects (Yao et al. 2017). Therefore, developing alternatives for chemical fungicides using active substances in plants, such as botanical fungicides, is urgently needed.

Plants produce more than 400,000 kinds of bioactive components, such as alkaloids, organic acids, flavonoids, phenols, and plant essential oils, most of which have anthelmintic, insecticidal, antifungal, or antibacterial activities (Yao et al. 2017). These bioactive compounds have a broad spectrum of target organisms, are safe for non-target organisms, and are characterized by low toxicity, low residue, easy degradation, and no target resistance (He et al. 2006; Yoon et al. 2013; Zhang et al. 2013a, b). Plant bioactive components are a key research topic for controlling many plant diseases and developing new botanical pesticides, with prospects of wide exploitation and utilization (Li 2017; Tang et al. 2018). Potato glycoalkaloids are steroids produced as secondary metabolites by potatoes (Guo et al. 2017). The main components of potato glycoalkaloids are $\alpha$-solanine and $\alpha$-chaconine (Zhao et al. 2013), which represent more than $95 \%$ of the total glycoalkaloids (Kodamatani et al. 2005). Previous studies have shown that potato glycoalkaloids have a wide range of biological activities (Qiao 2017), and can inhibit infection or growth of fungi, bacteria, viruses, and other plant pathogenic 
microorganisms, prevent insects from feeding or harming plants (Friedman 2004; Liang et al. 2017), exert protective effects on plants, and possess important medicinal value (Zhao et al. 2013). Fewell and Roddick (1993) reported that $\alpha$-solanine and $\alpha$-chaconinein potatoes can inhibit the growth of fungi such as Alternaria brassicicola, Ascobolus crenulatus, Rhizoctonia solani, and Phoma medicaginis. Furthermore, Zhao et al. (2013) showed that potato glycoalkaloids have high inhibitory effects on Alternaria porri and Cercosporella brassicae. Likewise, Ombra et al. (2014) found that potato extract had antibacterial activity against Bacillus cereus, Escherichia coli, and Pseudomonas aeruginosa under in vitro conditions.

Currently, potato glycoalkaloids extract has been noted to have an inhibitory effect on three economic forest pathogenic fungi: F. solani, Capnodium leaophilum, and Marssonina juglandis. Notably, the inhibitory effect on $F$. Solani was the strongest (Duo et al. 2017). However, the studies on control of $F$. solani disease using plant bioactive compounds as well as the antifungal mechanism of these compounds are limited. Therefore, in the study, the effects of potato glycoalkaloids extract on the ultrastructure, cell membrane permeability, and contents of reducing sugar, soluble sugar, soluble protein, and mycelial fat of $F$. solani were examined, and the inhibition mechanism was preliminarily determined. The results could provide a theoretical basis for prevention and control of economic forest diseases as well as for the development and utilization of plant-derived fungicides.

\section{Materials and Methods}

\section{Materials}

The potato is Qingshu variety No.9 being purchased from supermarket. The fresh potato samples were washed and dried in sunlight for several weeks to turn the potato skin green and allow germination. Subsequently, the green potato skin and buds were dried in a vacuum blast drying oven and pulverized into a powder using a plant pulverizer through an 80-mesh sieve and stored at $0-4^{\circ} \mathrm{C}$ until further use.

The test strain of $F$. solani was isolated from Lycium barbarum root rot in Gansu Province, China (Fang 1998), and its pathogenicity was confirmed based on Koch's postulates. After identification, the strain was stored at 0 $4^{\circ} \mathrm{C}$ until further use. Potato dextrose broth (PDB) and potato dextrose agar (PDA) were employed for fungal cultivation. The PDB comprised $200 \mathrm{~g}$ of peeled potato, 20 $\mathrm{g}$ of glucose, and $1000 \mathrm{~mL}$ of distilled water (neutral $\mathrm{pH}$ ). The PDA was prepared by adding 17-20 g of agar to the constituents of PDB. All reagents used were of domestic analytical grade and purchased from Gansu Zhongrui Chemical Co. Ltd., China.

\section{Extraction of potato glycoalkaloids}

Potato glycoalkaloids were extracted using an acetic acid extraction-ammonia precipitation method with slight modifications (Bo et al. 2012). In brief, $100 \mathrm{~g}$ of the potato sample was mixed with $400 \mathrm{~mL}$ of $5 \%$ acetic acid, stirred for 60 min (JB-1 magnetic stirrer, Shanghai Leici Xinjing Instrument Co. Ltd., China), and filtered (SHZ-D III circulating water vacuum pump, Gongyi Yuhua Instrument Co. Ltd., China). The residue was extracted twice with 200 $\mathrm{mL}$ of $5 \%$ acetic acid, and the filtrate was combined, and its $\mathrm{pH}$ adjusted to 11 with ammonia. After extracting three times with $200 \mathrm{~mL}$ of water-saturated $n$-butanol, the extracts were combined and dried on a rotary evaporator (RE-3000, Shanghai Yarong Biochemical Instrument Factory, China), and the residue mixed with $20 \mathrm{~mL}$ of methanol to obtain total glycoalkaloids extract. The mass concentration of the glycoalkaloids extract was $5 \mathrm{~g} \mathrm{~mL}^{-1}$.

\section{Effect of potato glycoalkaloids on ultrastructure of $F$. solani}

The $F$. solani was inoculated onto PDA at a concentration of $0.3036 \mathrm{~g} \mathrm{~mL}^{-1}\left(\mathrm{EC}_{50}\right)$, along with $2 \mathrm{~g} \mathrm{~mL}^{-1}$ potato glycoalkaloid extract, and incubated at $25^{\circ} \mathrm{C}$ for $48 \mathrm{~h}$. Subsequently, sterile filter paper strips $(0.7 \mathrm{~cm} \times 5 \mathrm{~cm})$ were placed around the colony (covering an area of $5 \mathrm{~cm} \times 5 \mathrm{~cm}$ ) and incubated at $25^{\circ} \mathrm{C}$. After $72 \mathrm{~h}$, the edge of the colony was sampled. The collected sample was fixed by double fixation with glutaraldehyde and citric acid (Zeng 2012), and observed and photographed under a transmission electron microscope (JEM2000EX; JEOL, Japan).

\section{Effect of potato glycoalkaloids on cell membrane permeability of $F$. solani}

The mycelia of $F$. solani were cultured in PDB for 4 days and washed four times with ultrapure sterile water. Then, the washed mycelia were freeze-dried to a constant weight (Labconco freeze drier, USA) and $1 \mathrm{~g}$ of the mycelia was transferred into $5 \mathrm{~mL}$ of potato glycoalkaloid $\left(\mathrm{EC}_{50}\right)$ extract and incubated at $25^{\circ} \mathrm{C}$ under constant shaking at $120 \mathrm{r}$ $\min ^{-1}$. Subsequently, conductivity of the culture broth was measured (DDB-303A digital conductivity meter, Shanghai Yidian Scientific Instrument Co. Ltd., China) hourly during 0-9 h. Finally, the culture broth was boiled in a water bath (HH-S6 digital display thermostat water bath, Jintan Medical Instrument Factory, China) for $10 \mathrm{~min}$ and conductivity was determined. The experiment was repeated thrice, with sterile water and methanol as controls. The permeability of cell membrane was expressed as relative permeability $(\%)=($ relative time conductivity value - initial conductivity value) / (kill conductivity value -initial conductivity value) $\times 100 \%$ (Shen 2014 ).

\section{Effect of potato glycoalkaloids on soluble mycoprotein of F. solani}

The effect of potato glycoalkaloids on soluble mycoprotein was determined by Coomassie Brilliant Blue G-250 staining 
(Song 2010). In brief, mycelia of $F$. solani were cultured in PDB for 4 days, and washed four times with ultrapure sterile water. Then, the washed mycelia were freeze-dried (Labconco) to a constant weight and $1 \mathrm{~g}$ of the mycelia was added to $5 \mathrm{~mL}$ of potato glycoalkaloids $\left(\mathrm{EC}_{50}\right)$ extract, and sampled at $0,2,4,6$, and $8 \mathrm{~h}$. The collected samples were centrifuged (D-37520 centrifuge, Heraeus Biofuge, Germany), and the absorbance of samples was recorded at $595 \mathrm{~nm}$ (Jenway $6505 \mathrm{UV} / \mathrm{Vis}$ UV Spectrophotometer; Gaonan Instrument (Shenzhen) Co. Ltd. China). The protein concentration was calculated according to the protein standard curve, and the experiment was repeated thrice, with sterile water and methanol as controls.

\section{Effect of potato glycoalkaloids on soluble sugar of $F$. solani}

The effect of potato glycoalkaloids on soluble sugar in $F$. solani was determined by anthrone colorimetry (Yao and $\mathrm{Xu}$ 1992). In brief, F. solani mycelia were cultured in PDB for 4 days, and then washed four times with ultrapure sterile water. Then, the washed mycelia were freeze-dried (Labconco) to a constant weight and $1 \mathrm{~g}$ of mycelia mixed with $5 \mathrm{~mL}$ of potato glycoalkaloids $\left(\mathrm{EC}_{50}\right)$ extract, and sampled at $0,1,2,4,6,8,10$ and $12 \mathrm{~h}$. Subsequently, collected samples were subjected to centrifugation (6000 $\mathrm{rpm}$; $5 \mathrm{~min}$ ), heated with anthrone reagent, and cooled to room temperature, and the absorbance of the samples measured at $620 \mathrm{~nm}$. The soluble sugar content was calculated according to the glucose standard curve, and the experiment was repeated thrice, with sterile water and methanol as controls.

\section{Effect of potato glycoalkaloids on reducing sugar of $F$. solani}

The effect of potato glycoalkaloids on reducing sugar in $F$. solani was determined by 3,5-dinitrosalicylic acid (DNS) method (Chen 2002). In brief, F. solani mycelia were cultured in PDB for 4 days, and washed four times with ultrapure sterile water. Then, the washed mycelia were freeze-dried (Labconco) to a constant weight and $1 \mathrm{~g}$ of mycelia was added to $5 \mathrm{~mL}$ of potato glycoalkaloid $\left(\mathrm{EC}_{50}\right)$ extract, and sampled hourly during $0-8 \mathrm{~h}$. Subsequently, 1 $\mathrm{mL}$ of the collected samples was respectively subjected to centrifugation $(6000 \mathrm{rpm} ; 5 \mathrm{~min})$, and $0.5 \mathrm{~mL}$ of the supernatant was mixed with $1.5 \mathrm{~mL}$ of distilled water and $1.5 \mathrm{~mL}$ of DNS reagent to determine the absorbance at 520 $\mathrm{nm}$. The reducing sugar content was calculated according to the standard curve, and the experiment was repeated thrice, with sterile water and methanol as controls.

\section{Effect of potato glycoalkaloids on fat content of $F$. solani}

The oil weight method was employed for sample processing and fat content determination ( $\mathrm{Li}$ 1987). The F. solani mycelia were cultured in PDB for 4 days and washed four times with ultrapure sterile water. Then, the washed mycelia were freeze-dried (Labconco) to a constant weight and $1 \mathrm{~g}$ of the mycelia was added to $5 \mathrm{~mL}$ of potato glycoalkaloids $\left(\mathrm{EC}_{50}\right)$ extract, and sampled at 24,48 , and $72 \mathrm{~h}$. Subsequently, the collected samples were filtered (SHZ-D III circulating water vacuum pump) and rinsed with redistilled water four times; the obtained wet hyphae were dried at $60-80^{\circ} \mathrm{C}$ for $4 \mathrm{~h}$, smashed with a mortar and pestle, and filtered through a mesh sieve to obtain dried powder. The procedure was repeated thrice, and sterile water and methanol were used as controls. For fat content determination, the Soxhlet extractor was cleaned, heated in a blast drying oven at $105^{\circ} \mathrm{C}$ for $20 \mathrm{~min}$, cooled to room temperature, and weighed $(\mathrm{m})$. Then, $12-\mathrm{cm}$ quantitative filter paper was weighed $\left(\mathrm{m}_{1}\right)$ and made into a bucket, and 2 $\mathrm{g}$ of the dried sample powder were added to the filter paper bucket and weighed $\left(\mathrm{m}_{2}\right)$. The difference between the two masses indicated the quality of the dried sample powder $\left(\mathrm{m}_{2}-\mathrm{m}_{1}\right)$. Subsequently, the dried sample was soaked in petroleum ether overnight, and heated in a thermostat water bath for $65^{\circ} \mathrm{C}$. Reflux extraction was performed for $12 \mathrm{~h}$ using a Soxhlet fat extractor, and then the extract was heated at $100^{\circ} \mathrm{C}$ for $8 \mathrm{~h}$, cooled to room temperature, and weighed $\left(\mathrm{m}^{\prime}\right)$. Crude fat was calculated as follows: crude fat $(\%)=$ $\left(\mathrm{m}^{\prime}-\mathrm{m}\right) /\left(\mathrm{m}_{2}-\mathrm{m}_{1}\right) \times 100 \%$.

\section{Statistical analysis}

All the above measurements were repeated at least three times. The results were expressed as mean value \pm standard errors calculated by Microsoft Excel 2007. The variance was examined using SPSS 19.0 and the difference investigated by employing Duncan's new complex range method (Zhang 2013).

\section{Results}

\section{Effect of potato glycoalkaloids on ultrastructure on $F$.} Solani

Once the cell wall or cell membrane is destroyed, the cell cannot maintain its inherent structure in morphology, and the mycelium will be twisted, deformed, or even broken. In this study, the controls without potato glycoalkaloids treatment presented thin and uniform cell walls, complete structure, hyphae surrounded by a continuous outer layer, intact internal tissue structure, no extravasation of cell contents, normal development, and clearly visible vacuoles, mitochondria, and other organelles (Fig. 1A). However, after treatment with $\mathrm{EC}_{50}$ potato glycoalkaloids, the fungal cell walls became thinner and irregular, cell internal structure was disrupted, and some membrane structures were incomplete (Fig. 1B). Furthermore, after treatment with $2 \mathrm{~g} \mathrm{~mL}^{-1}$ potato glycoalkaloids, cell walls of mycelia had a bubble shape, outer layer components were altered, 
cell wall structure was incomplete, the outer cell membrane was discontinuous, structure of mitochondria and other organelles was not obvious, and extracellular inclusions were exuded (Fig. 1C). In contrast, following treatment with methanol, the cell wall structure was clear, mitochondria and ribosomes were clearly visible, and the vacuolar structure was intact, indicating that methanol did not affect antibacterial activity of potato glycoalkaloids (Fig. 1D). These findings indicated that potato glycoalkaloids destroyed the cell surface morphology of $F$. solani, severely damaging the cytoplasm, mitochondria, and other organelles, as well as increasing the cell membrane permeability and so causing leakage of cell contents.

Effect of potato glycoalkaloids on cell membrane permeability of $F$. solani

Selective permeability is the most basic function of the cell membrane. If the cell loses this function, the cell will die. In this study, the Fig. 2 shows the effects of potato glycoalkaloids on the cell membrane permeability of $F$. solani. The relative cell membrane permeability increased with time in both the control and treatment groups. However, the relative cell membrane permeability was significantly higher for the treatment compared with the control group. In both the control and treatment groups, the relative cell membrane permeability rapidly increased during $1-4 \mathrm{~h}$, with a greater increase for the treatment than the control group. After $4 \mathrm{~h}$, the difference in relative cell membrane permeability quickly broadened between the two groups, indicating that the $F$. solani cell membrane damage caused by potato glycoalkaloids at $\mathrm{EC}_{50}$ concentration intensified at $4 \mathrm{~h}$. Subsequently, the relative cell membrane permeability of the control group gradually decreased during 4-9 $\mathrm{h}$, whereas that of the treatment group increased by $25.2 \%$ at $9 \mathrm{~h}$, and remained stable at 8 and $9 \mathrm{~h}$.

\section{Effect of potato glycoalkaloids on soluble protein of $F$.} solani

Material metabolism is divided into anabolism and catabolism, both of which maintain dynamic balance in normal life activities. When this balance is broken, it will cause diseases of the organism and even death. In this study, the soluble protein leakage in the treatment group exhibited an upward trend with time, which significantly differed from that in the control group (Fig. 3). During 0-6 h, soluble protein leakage in the treatment group increased from 66.50 to $169.51 \mu \mathrm{gmL}^{-1}$, which was much higher than that in the control group. However, during 6-24 h, the soluble protein leakage in the treatment group gradually decreased with time, possibly due to consumption of soluble proteins by newly formed cells of $F$. Solani for growth. After $24 \mathrm{~h}$, the soluble protein leakage in the treatment and control groups gradually increased and stabilized.
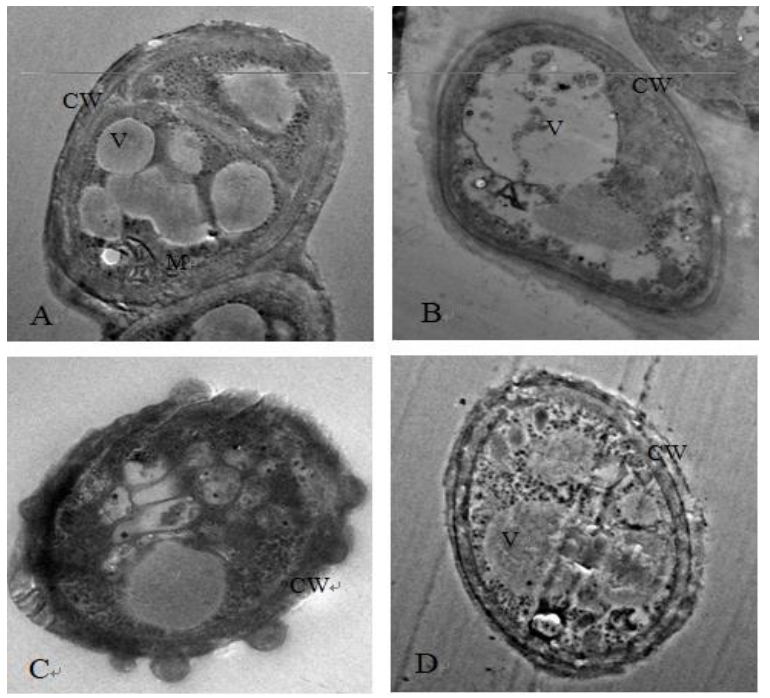

Fig. 1: Effect of potato glycoalkaloids on ultrastructure of $F$. solani $(2550 \times)$

A: Control 1 (sterile water); B: Treatment $1\left(\mathrm{EC}_{50}\right)$; C: Treatment $2\left(2 \mathrm{~g} \mathrm{~mL}^{-1}\right)$; $\mathbf{D}$ : Control 2 (methanol).

CW: Cell wall; V: Vacuole; M: Mitochondrion

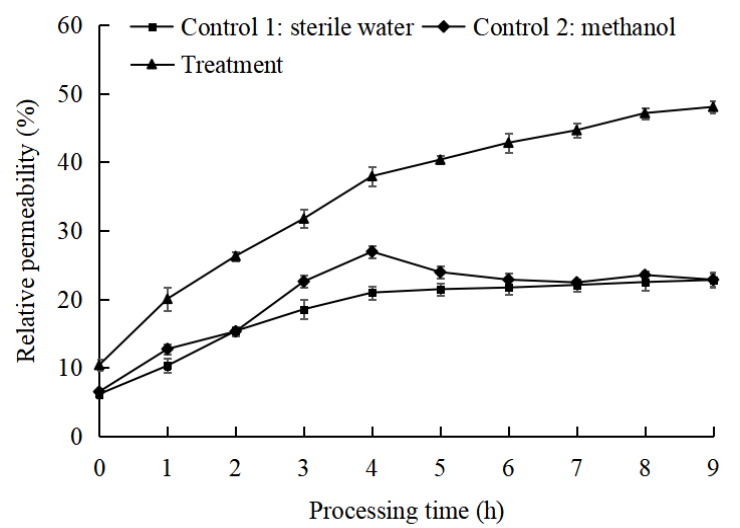

Fig. 2: Effect of potato glycoalkaloids on cell membrane permeability of $F$. solani

Effect of potato glycoalkaloids on soluble sugar of $F$. solani

Soluble sugar leakage in the treatment group significantly differed from that in the control with time (Fig. 4). During 0-24 h, soluble sugar leakage in the treatment group increased from 117.4 to $132.5 \mu \mathrm{g} \mathrm{mL}^{-1}$, which was much higher than that in the control group. However, after $24 \mathrm{~h}$, leakage in the treatment group decreased with time owing to consumption of soluble sugar in the extracellular fluid by newly formed $F$. solani cells for growth.

Effect of potato glycoalkaloids on reducing sugar content of $F$. solani

The reducing sugar content in the extracellular fluid 
significantly differed between the treatment and control group with time (Fig. 5). In both groups, the reducing sugar content in the extracellular fluid sharply decreased during 0 $2 \mathrm{~h}$, but gradually reduced during $2-72 \mathrm{~h}$, indicating that potato glycoalkaloids significantly decreased the absorption and utilization of reducing sugar by $F$. solani.

\section{Effect of potato glycoalkaloids on fat content of $F$. solani}

The fat content in the extracellular fluid of both the treatment and control groups increased during $0-48 \mathrm{~h}$, with significantly higher fat leakage for the treatment compared with the control group (Fig. 6). The fat content in the extracellular fluid of the treatment group increased by 54.20 and $52.07 \%$, compared with sterile water and methanol control groups at $48 \mathrm{~h}$, respectively, indicating that potato glycoalkaloids damaged the cell structure and caused fat content leakage from $F$. solani plasma membrane. However, after $48 \mathrm{~h}$, fat content in the extracellular fluid of both treatment and control groups showed a downward trend, possibly resulting from a weakening effect of potato glycoalkaloids or a self-remediation mechanism of $F$. solani.

\section{Discussion}

Plant bioactive substances mainly target the cell membrane of fungi by altering membrane stability and causing damage to the membrane structure and extravasation of inclusions, ultimately resulting in fungicidal or fungistatic effect (Zhou et al. 2014). Previous studies have shown that glycoalkaloids predominantly combine with sterols in the fungal cell membrane, forming a complex that destroys membrane integrity and causes loss of normal membrane function (Sun 2014). In the present study, transmission electron microscopy showed that $F$. solani morphology was distorted after potato glycoalkaloids treatment, and that some cell walls were blurred or even lost. Additionally, structure of the cell and vacuolar membranes was destroyed and the organelles distorted. These observations indicated that potato glycoalkaloids can affect the surface morphology of $F$. solani, leading to incomplete membrane structure and causing serious damage to cytoplasm and mitochondria, consistent with the effect of pyrolin on Monilinia fructicola (Wu et al. 2009), ethyl acetate extract of amaranth on Xanthomonas citri (Liao et al. 2017), and water-soluble chitosan on the ultrastructure of Fusarium (Jia et al. 2016).

Electrical conductivity can indirectly reflect cell membrane permeability, and a higher electrical conductivity of a culture broth signifies enhanced electrolyte leakage and increased damage to cell membranes (Shang 2017). Peng et al. (2017) showed that extract of Cynanchum atratum could enhance the cell membrane permeability of Penicillium italium, while Zhang et al. (2008) revealed that the extract of Xanthium sibiricum induced changes in membrane permeability of Botrytis cinerea, resulting in increased

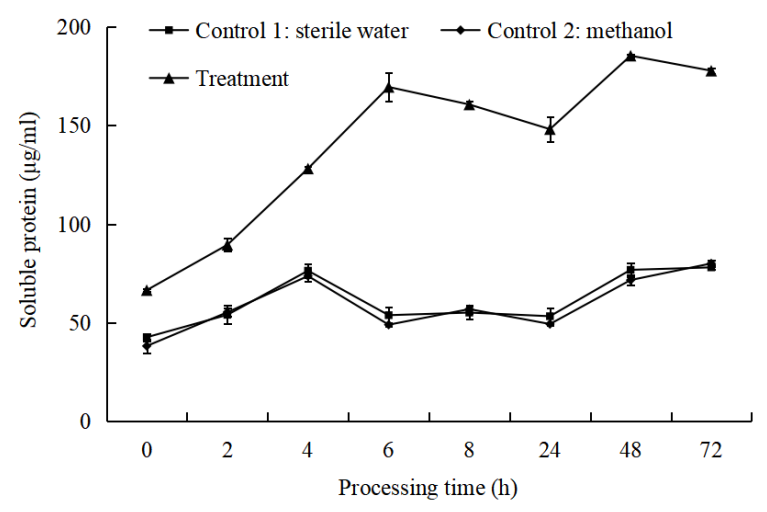

Fig. 3: Effect of potato glycoalkaloids on soluble protein leakage of $F$. solani

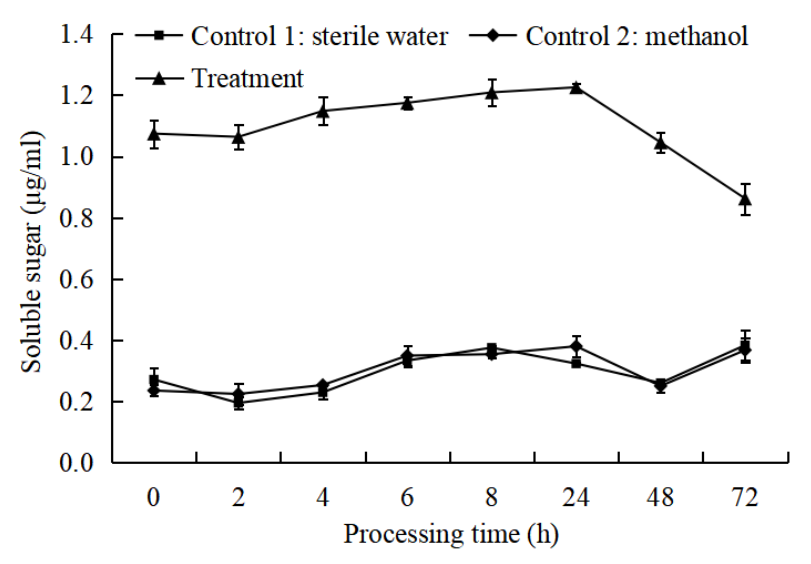

Fig. 4: Effect of potato glycoalkaloids on soluble sugar leakage of F. solani

conductivity of the culture broth. Furthermore, Liu et al. (2018a) found that the total saponins and total ginsenoside from ginseng stem and leaf can induce changes in the permeability of the mycelium membrane of $F$. solani, respectively, leading to increased conductivity of the culture broth. Liu et al. (2018b) showed that limonene can increase the cell membrane permeability of Pseudomonas aeruginosa and destroy its cell morphology and integrity, thus effectively inhibiting its growth. Similarly, in the present study, the cell membrane permeability of $F$. solani increased after treatment with potato glycoalkaloids, and transmission electron microscopy revealed leakage of intracellular contents and destruction of cell membrane structure. These results showed that the cell membrane and integrity of $F$. solani were destroyed by potato glycoalkaloids, which directly affected the physiological functions of the cell membrane, such as exchange of intracellular and extracellular substances and regulation of cell growth, leading to disturbance infungal metabolism.

It must be noted that plant bioactive compounds also affect the morphology and structure of fungal mycelia, causing deformity, kinking, swelling, and lysis. As a result, the mycelial soluble protein and soluble sugar can leak into 
the culture medium (Zhou et al. 2011; Fan et al. 2015; Zhang et al. 2016). In fungi, soluble protein mainly comprises various enzymes involved in metabolism. During growth, the fungi secrete proteins that penetrate the cell membrane into the thallus fluid through osmosis. Thus, changes in the content of these proteins reflect alteration in the total cellular metabolism (Liu et al. 2016). Sugar catabolism provides the energy needed for fungal growth, and inhibition of the absorption and utilization of sugar could lead to lack of energy required by the fungi, affecting growth and propagation of the thallus (Liu et al. 2016). The total lipid content in the fungal cell membrane affects cell membrane fluidity, and a decrease in the total lipid content may lead to a reduction in cell membrane fluidity (Shang 2017). Thus, one approaches to achieve fungicidal or fungistatic effect is to inhibit fungal metabolism (Zhou et al. 2014). In the present study, the contents of total sugar, protein, and fat in $F$. solani initially increased and then decreased with time after treatment with potato glycoalkaloids. However, the content of reducing sugar decreased in $F$. solani treated with potato glycoalkaloids, but significantly increased in control cells without glycoalkaloids treatment. Similar findings were also reported by $\mathrm{Wu}$ (2008), who showed that the contents of total sugar, reducing sugar, protein, and fat in $B$. cinerea treated with propamidine were significantly higher than those in control B. cinerea without treatment, indicating that plant bioactive compounds inhibited catabolism in fungi. Biological catabolic systems are complex, and disturbance in a certain catabolic link can obstruct the entire catabolic process, threatening life of the organism. However, selfremedial mechanisms can overcome the blocked metabolic processes to continue life activities (Zeng 2012). Therefore, it is possible that self-remedial mechanisms of $F$. solani allowed the fungal cells to thrive after treatment with potato glycoalkaloids, resulting in an initial increase and subsequent decrease in contents of total sugar, protein, and fat with treatment duration.

\section{Conclusion}

Results in the present study showed that potato glycoalkaloids significantly affected the morphological structure of $F$. solani. Treatment with potato glycoalkaloids resulted in bubbly and undulated mycelial cell walls, incomplete outer structure, discontinuous cell membrane, disordered structure of mitochondria and other organelles, and visible extracellular contents. The material metabolism analysis demonstrated that potato glycoalkaloids destroyed the selective permeability of fungal cell membranes and causing extravasation of large quantities of internal lipids, proteins, and sugars. This hindered the hydrolysis of reducing sugars, affecting the absorption and utilization of nutrients, and ultimately inhibiting catabolism in fungi. However, knowledge of the specific antifungal mechanism of potato glycoalkaloids is limited. Therefore, further

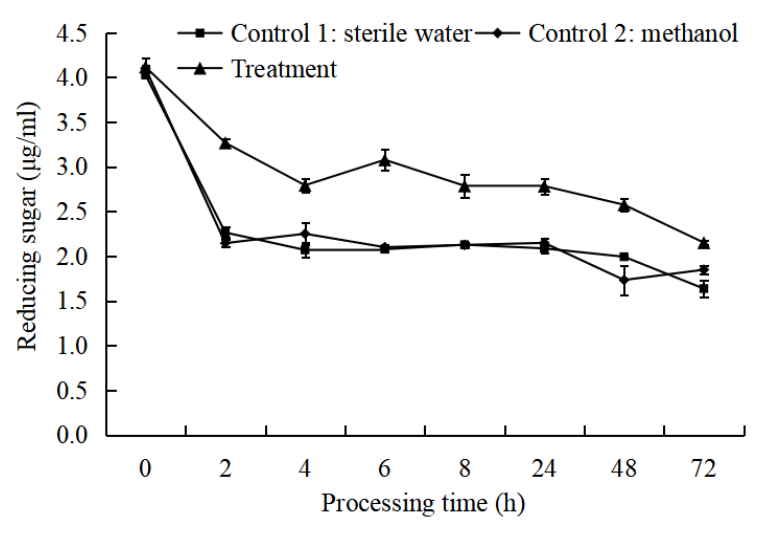

Fig. 5: Effect of potato glycoalkaloids on reducing sugar content of $F$. solani

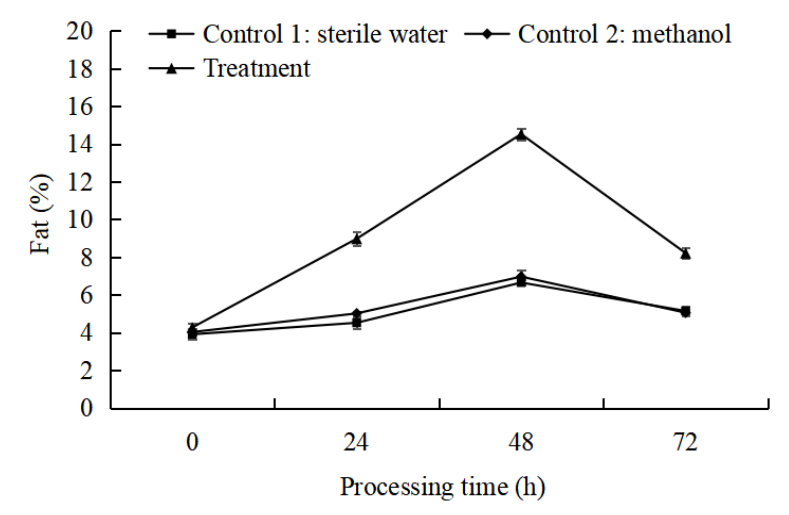

Fig. 6: Effect of potato glycoalkaloids on fat content of $F$. solani

research on the effects of potato glycoalkaloids on fungal respiratory metabolism (e.g., related enzymes activities) and energy metabolism (e.g., inhibition of electron transport and oxidative phosphorylation, and information expression of nucleic acids and other molecular substances) is necessary for a better understanding of the antifungal mechanism of these compounds and for acquiring comprehensive and systematic theoretical support for the development and utilization of botanical pesticides.

\section{Acknowledgements}

The work was supported by grants from the National Natural Science Foundation of China (32060341), Special Funds for Discipline Construction of Gansu Agricultural University (GAU-XKJS-2018-096), and Supporting Funds for Youth Mentor of Gansu Agricultural University (GAUQDFC-2018-07) and Postdoctoral Research Projects (2015GSZYZZ002). We thank International Science Editing (http://www.internationalscienceediting.com) for editing this manuscript.

\section{Author Contributions}

JH planned the experiments, JH and TTD interpreted the 
results, JH, TTD and WC contributed to writing and XYZ statistically analyzed the data and prepared illustrations.

\section{Conflicts of Interes}

The authors declare that they have no conflict of interest.

\section{Data Availability}

The data will be made avaialble on acceptable requests to the corresponding author.

\section{Ethics Approval}

Not applicable.

\section{References}

Bo LL, XY Sun, H Lin, MJ Dai, JP Niu, JW Zhang, D Wang (2012). Extraction of glycoalkaloids from potatoes. J Anhui Agric Sci 40:1448-1491

Chen W, J He, TT Duo, RJ Xue, HJ Xu, HJ Yang (2017). Laboratory toxicity test of several fungicides against root rot pathogens of Lycium barbarum. J Gansu Agric Univ 52:109-113

Chen YQ (2002). Determination of reducing sugar and total sugar content. In: Methods and Techniques of Biochemistry Experiment, pp:97-99. Science Press, Beijing, China

Du B (2017). Classification and research status of Fusarium. J Taiyuan Univ 35:68-70

Duo TT, J He, W Chen, JW Zhang, SH Feng, HY Ma, J Du (2017). Antibacterial activity of potato glycoalkaloids and their effects on cell membrane permeability. J Gansu Agric Univ 52:50-54

Fan MC, YJ Sun, WX Li, XK Kou (2015). Screening and mechanism study of antibacterial effect of natural plant extracts. J Chin Inst Food Sci Technol 15:180-185

Fang ZD (1998). Isolation and culture of fungi. In: Research Methods of Plant Disease, pp:122-145. China Agric Press, Beijing, China

Fewell AM, JG Roddick (1993). Interactive antifungal activity of the glycoalkaloids $\alpha$-solanine and $\alpha$-chaconine. Phytochemistry 33:323328

Friedman M (2004). Analysis of biologically active compounds in potatoes (Solanum tuberosum), tomatoes (Lycopersicon esculentum), and jimson weed (Datura stramonium) seeds. $J$ Chromatogr A 1054:143-155

Guo HX, JJ Zhang, R An, Y Qiao, WH Shi, J Shi, JW Zhang (2017). Study on the regulation of glycosidic alkaloid synthesis in green tissues of potato aboveground parts. J Hortic 44:1105-1115

He J, ZQ Ma, X Zhang (2006). An overview of botanical pesticides. $J N W$ Agric For Univ 34:79-85

Jia RX, M Qiu, JY Huang, Y Zhou (2016). Antimicrobial mechanism of chitosan and its derivatives against Fusarium. Chin J Food 16:70-75

Kodamatani H, K Saito, N Niina, S Yamazaki, Y Tanaka (2005). Simple and sensitive for determination of glycoalkaloids in potato tubers by high-performance liquid chromatography with chemiluminescence detection. J Chromatogr A 1100:26-31

Li C (1987). Separation with volatile. In: Principles and Techniques of Food Analysis, ${ }^{\text {st }}$ Edition, pp: 12-30. Sci Technol Lit Press, Beijing, China

Li CB (2017). Bioactivity of Ten Plant Extracts against Pathogenic Bacteria in Tea Leaves. Huazhong Agricultural University, College of Science, Wuhan, Hubei, China

Li SJ, TH Zhu, TM Cen, S Han (2016). Screening, identification, colonization and control effect of Bacillus spp. against root rot of Zanthoxylum bungeanum. J N W Univ Agric For Sci Technol (Nat Sci Edn) 44:114-122

Liang KH, LG Lu, DZ Zhu, H Zhu (2017). Research progress of potato glycoalkaloids. Food Res Dev 38:195-199
Liao SL, W Yin, XL Liao, Y Zhang (2017). Study on the inhibition and mechanism of ethyl acetate extract from Amaranth on Citrus canker. J Hunan Agric Univ (Nat Sci Edn) 43:544-550

Liu FF, AH Zhang, FJ Lei, YH Xu, LX Zhang (2018a). Inhibitory effect of total saponins from ginseng stem and leaf on Fusarium oxysporum and its bacteriostatic mechanism. J Jilin Agric Univ 40:85-91

Liu X, JN Wang, WX Chen, RH Chen, GF Zhang (2018b). The antibacterial activity and mechanism of limonene against Pseudomonas aeruginosa. Food Industr Sci Technol 39:1-59

Liu JY, QQ Zhao, ZY Zhang, H Den, N Qi, H Li (2016). Preliminary study on the antibacterial activity and mechanism of sterols in seed oil of Xanthoceras sorbifolia L. Chin Oil 41:29-33

Ombra MN, F Fratianni, T Granese, F Cardinale, A Cozzolino, F Nazzaro (2014). In vitro antioxidant, antimicrobial and anti-proliferative activities of purple potato extracts (Solanum tuberosum cv. vitelotte noire) following simulated gastro-intestinal digestion. Nat Prod Res 14:1-5

Peng X, YH Chen, JY Chen (2017). Antifungal mechanism of Cynanchum atratum Bunge extracts on Penicillium italicum and control effect on blue mold of navel orange. J Plant Pathol 47:398-405

Qiao Y (2017). Identification and Functional Analysis of miRNAs Induced by Photoinduced Glucoside Alkaloid Metabolism in Potato. Gansu AgriculturalUniversity, College of Agronomy, Lanzhou, Gansu, China

Rampersad S (2010). First report of Fusarium solani causing fruit rot of sweet pepper in Trinidad. Plant Dis 94:1375

Shang CY (2017). Study on the Antibacterial Mechanism of $\beta$-pinene on Penicillium Citrinum. Huazhong Agricultural University, College of Food Science and Technology, Wuhan, Hubei, China

Shen Y (2014). Study on the Screening and Identification of Endophytic Actinomycetes from Maize and the Mechanism of Inhibition of Maize. Northeast Agricultural University, College of Agronomy, Harbin, Heilongjiang, China

Song L (2010). Inhibition and Mechanism of BIT against Botrytis Cinerea, Northwest University, College of Life Science, Xi'an, Shaanxi, China

Sun PZ (2014). Antimicrobial Activity of Potato Alpha-solanine against Botrytis Cinerea In vitro. Inner Mongolia Agricultural University, College of Food Science and Engineering, Hohhot, Inner Mongolia, China

Tang XH, LY Zhong, T Tang, W Fli, X Li, L Jiang, G Zhao, JL Zhao (2018). Inhibition of extracts from six kinds of perfume plants on Rhizoctonia solani of buckwheat. J Jiangxi Agric Univ 40:89-95

Tang XM, TY Lin, SS Zhou, GF Li, P Liu, ZF Ye, ZY Wu, DS Wang, LW Zhu (2017). Isolation and identification of pathogenic bacteria of pear root rot and screening of effective control agents. J Nanj Agric Univ 40:76-83

Wang YX, YK Xu, ZM Li (2014). Selection of 8 fungicides on main pathogens of seedling blight of Acanthopanax senticosus. Jilin Agric 24:12

Wu FL (2008). Preliminary Study on the Antibacterial Mechanism of Propane Oxime against Botrytis Cinerea. Northwest A\&F University, College of Food Science and Engineering, Yangling, Shaanxi, China

Wu ZY, Y Wang, QJ Ai (2009). Inhibitory effect of pyrolysin on peach brown rot pathogen and its bacteriostatic mechanism. Chin Agric Sci 42:2784-2792

Yao HW, KK Ge, JL Pan, WL Liu, L Ma (2017). Screening of antibacterial activity of extracts from 29 plants such as Syringa. J N E For Univ 45:35-39

Yao LH, Q Xu (1992). Simplified study on the determination of total sugar content in food by anthrone colorimetry. Food Industr 3:40-42

Yoon MY, B Cha, JC Kim (2013). Recent trends in studies on botanical fungicides in agriculture. Plant Pathol J 29:1-9

Zeng R (2012). Study on the Antibacterial Active components, antibacterial mechanism and the effect on Citrus Preservation and Preservation of Impatiens balsamina. Nanchang University, College of Life Science and Food Engineering, Nanchang, Jiangxi, China

Zhang L (2013). Analysis of variance. In: The Application of SPSS19.0 (Chinese version) in Biostatistics, $3^{\text {rd }}$ edn, pp:16-35. Xiamen University Press, Xiamen, China 
Zhang W, JJ Liao, GL Zhu, H Zhang, XL Duan, SS Zhu, M Yang (2013a). Study on the inhibitory activity of 8 plant volatiles and extracts against root rot on Panax notoginseng. Chin Agric Sci Bull 29:197201

Zhang X, ZF Wu, W Li, ZQ Ma, JT Feng (2013b). New progress in the development and application of botanical pesticides-Introduction to special biological activities. Pestic Sci Manage 34:24-31

Zhang XH, J He, HM Shen (2008). Inhibitory effect of Xanthium sibiricum extract against Botrytis cinerea and its bacteriostatic mechanism. $J$ Grass Ind 3:99-104

Zhang XM, QL Xue, R Xiao, LZ Zhao, Q Lin, YJ Hu (2016). Bacteriostatic mechanism of extracts from mistletoe against Staphylococcus aureus. Mod Food Sci Technol 32:82-88

Zhao QF, L Liu, QX Li, HY Li (2012). Study on the inhibition effects of 15 plant aqueous extracts to the growth of Angelica sinensis root rot fungi. J N E Norm Univ (Nat Sci Edn) 48:66-69
Zhao XS, SY Li, DJ He, J Wang (2013). Study on the structure-activity relationship of potato glycoalkaloids against fungal activity. Food Ind Sci Technol 34:159-163

Zhao YL, W Wang, TT Pei, G Tao (2018). Isolation and identification of the pathogen of mango malformation in Guizhou. $S$ W Chin J Agric Sci 31:494-499

Zheng L, J Zhang, WJ Ma, Y Pen, TH Zhu (2016). Effects of Fusarium solani on physiological indexes of resistance of different varieties of walnut. Guangxi Plants 36:651-657

Zhou L, BY Yun, YJ Wang, MJ Xie (2011). Antimicrobial mechanism of emodin against Staphylococcus aureus. Chin J Biochem Mol Biol 27:1156-1160

Zhou MJ, CP Wan, JY Chen (2014). Screening of high-efficiency antimicrobial agents of Chinese herbal medicine against Citrus green mold and their antimicrobial mechanism. Mod Food Sci Technol 30:144-149 